\title{
Systemic moxifloxacin vs amoxicillin/metronidazole adjunct to non-surgical treatment in generalized aggressive periodontitis
}

\author{
Esra Guzeldemir-Akcakanat ${ }^{1}$, Cem-Abdulkadir Gurgan ${ }^{2}$ \\ ${ }^{1}$ Department of Periodontology, Faculty of Dentistry, Kocaeli University, Kocaeli, Turkey \\ ${ }^{2}$ Department of Periodontology, Faculty of Dentistry, Erciyes University, Kayseri, Turkey
}

Correspondence:

Kocaeli University

Dis Hekimligi Fakultesi

Periodontoloji AD. Yuvacik Yerleskesi

41190 Yuvacık-Başiskele-Kocaeli

Turkey,

esragd@yahoo.com

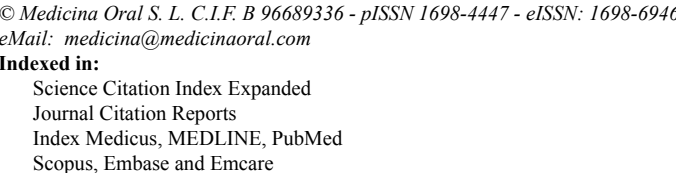

Received: $16 / 12 / 2014$ Accepted: $12 / 03 / 2015$

\begin{abstract}
Background: The objective of this randomized clinical study was to evaluate the effect of systemic administration of moxifloxacin compared to amoxicillin and metronidazole, combined with non-surgical treatment in patients with generalized aggressive periodontitis (GAgP) in a 6-month follow-up.

Material and Methods: A total of 39 systemically healthy patients with GAgP were evaluated in this randomized clinical trial. Periodontal parameters were recorded at the baseline during the $1^{\text {st }}, 3^{\text {rd }}$ and $6^{\text {th }}$ month. Patients received either $400 \mathrm{mg}$ of moxifloxacin per os once daily or $500 \mathrm{mg}$ of metronidazole and $500 \mathrm{mg}$ amoxicillin per os three times daily for 7 days consecutively.

Results: No significant differences between groups were found in any parameters at the baseline. Both groups led to a statistically significant decrease in all clinical periodontal parameters compared to the baseline (PI, $p<0.001$ and GI, PD, BOP, CAL, $p<0.01$ ). There were no differences between the $1^{\text {st }}$ and $3^{\text {rd }}$ months or the $3^{\text {rd }}$ and $6^{\text {th }}$ months for clinical parameters in the groups. Also, no intergroup difference was observed in any parameters at any time, except the gingival index at $6^{\text {th }}$ months.

Conclusions: Systemic administration of moxifloxacin as an adjunct to non-surgical treatment significantly improves clinical outcomes and provides comparable clinical improvement with less adverse events to that of combination of amoxicillin and metronidazole in the treatment of GAgP.
\end{abstract}

Key words: Aggressive periodontitis, amoxicillin, metronidazole, moxifloxacin, nonsurgical periodontal debridement. 


\section{Introduction}

Aggressive periodontitis (AgP) is an inflammatory periodontal disease, which is complex, multifactorial, and destructive.

$\mathrm{AgP}$ has been treated like other forms of periodontitis. The established treatment of periodontitis involves cause-related therapy, which includes: maintenance of oral hygiene, scaling and root planing (SRP), and surgeries of affected sites. Contrary to gingivitis and chronic periodontitis, mechanical non-surgical treatment does not always provide expected results in the treatment of AgP. In these cases, antibiotics may be used as an adjunct to treatment for eliminating or reducing the number of specific microorganisms and improving clinical parameters when compared with SRP alone (1-4). The American Academy of Periodontology (AAP) and the European Federation of Periodontology (EFP) were reported that patients with GAgP may have benefit from the adjunctive systemic administration of antibiotics $(1,5,6)$.

Amoxicillin is a moderate spectrum; bacteriolytic $\beta$-lactam antibiotic, and metronidazole is active against anaerobic bacteria. SRP combination with metronidazole and amoxicillin therapy was found to be more effective in suppressing P.g. and eradication of A.a. and preventing re-colonization of A.a. because of the synergistic effect of this combination and their wide spectrum of activity. It was found to be superior to azithromycin, doxycycline, and metronidazole in the treatment of GAgP.

Moxiflocaxin is a fourth generation fluoroquinolone antibiotic and exhibits good tissue penetration and high oral bioavailability. It has improved activity against $\mathrm{Gr}$ $(-)$, aerobic and anaerobes and has good activity against putative periodontal pathogens located within biofilm or intracellulary (7).

To the best of our knowledge, there is no study that evaluates the effect of moxifloxacin adjunct to SRP in the treatment of GAgP.

The aim of this study was to evaluate the impact of adjunctive systemic moxifloxacin; compared to the use of adjunctive systemic amoxicillin and metronidazole during full-mouth SRP based on the success of the treatment of patients with GAgP along with a 6-month follow-up.

\section{Material and Methods}

This study was a single-center, randomized, paralleldesign clinical trial with 6 month follow-up. The study protocol was approved by the Ethics Committee of the Medical Faculty of Kocaeli University (KOU KAEK 5/9). This clinical trial is registered; the identifier number is NCT02223702 (www.clinicaltrials.gov). The study protocol explained to the patients. From patients who willing to participate to the study, written informed consent was obtained and included the study.

The periodontal diagnosis of subjects with GAgP was performed according to the 1999 International World
Workshop for a Classification of Periodontal Diseases and Conditions. Patients were included if they were between 18 and 35 years of age and otherwise healthy. Subjects were excluded if they had any known systemic diseases or conditions that can/could influence the periodontal status, allergies to quinolones, penicillin or metronidazole, a history of antibiotic therapy, or periodontal treatment within the preceding six months.

\section{- Periodontal Examination}

The full-mouth clinical periodontal measurements were recorded at 6 sites per tooth, including plaque index $(\mathrm{PI})$, gingival index (GI), probing depth (PD), bleeding on probing (BOP) and clinical attachment loss (CAL).

- Nonsurgical treatment

Prior to treatment, all subjects had gone through motivation sessions for oral hygiene. Following periodontal measurements, full-mouth supragingival scaling using an ultrasonic scaler and polishing was performed. A toothbrush, toothpaste and an interproximal toothbrush were provided to all subjects. One week later, the patients were examined for plaque accumulation and oral hygiene. The patients who cannot maintain proper oral hygiene were excluded from the study. Only 39 patients fulfilled the qualification criteria for enrollment for the present study.

Subjects were randomly assigned to receive one of the two treatment groups. The moxifloxacin (MXF) group received SRP and adjunctive systemic antibiotic, 400 mg MXF (1x1, 7 days). The amoxicillin and metronidazole $(\mathrm{AMX}+\mathrm{MET})$ group received a combination of $500 \mathrm{mg}$ of amoxicillin and $500 \mathrm{mg}$ metronidazole (3x1, 7 days). The subjects were instructed to take the first dose of the antibiotics in the morning of the first session. SRP were performed during 2 consecutive days in 24-h under the local anesthesia. On each day, SRP were performed in 2 quadrants using ultrasonic scalers and manual instruments. The endpoint of SRP was a tactile, smooth root surface.

Patients used a $0.2 \%$ chlorhexidine digluconate rinse ( $2 \times 1,30$ days) and brushed their teeth by toothbrushes and interproximal toothbrushes twice a day. Patients asked to report any adverse events and side effects of the antimicrobial agents.

Subjects were monitored one week after the second SRP session. At this session, antibiotic intake and adverse events were questioned; oral hygiene was controlled. Subjects were screened at 1, 3 and 6 months after completion of SRP. During these sessions, periodontal indices and any medical history change; especially whether antibiotic therapy had been prescribed for any reason was recorded.

- Statistical Analysis

The reliability of continuous variables was expressed as the SD of the differences divided by 2. According to the reliability analysis for PD and CAL, the measurement 
errors were 0.13 and 0.11 , respectively. Cohen's $\mathrm{K}$ was employed to describe the reliability of discrete PI and GI values. Based on the duplicate measurements, the kappa values of PI and GI were $0.76 \pm 0.04$ and $0.86 \pm 0.05$, respectively.

Depending on the normality in the distribution of the clinical parameters, Mann-Whitney- $U$ and independent T-test were used for the differences between the groups. The changes in clinical parameters among different evaluation periods for each group were analyzed using Friedman and the repeated measure ANOVA test, where applicable. Additionally, when the $\mathrm{p}$ value from the Friedman test was statistically significant, multiple comparison tests were used to ascertain which evaluation time point differed from the others.

\section{Results}

Figure 1 shows flow diagram of the present study. A total of 39 subjects were enrolled into the present study; baseline demographic variables and clinical periodontal parameters are shown in table 1 .

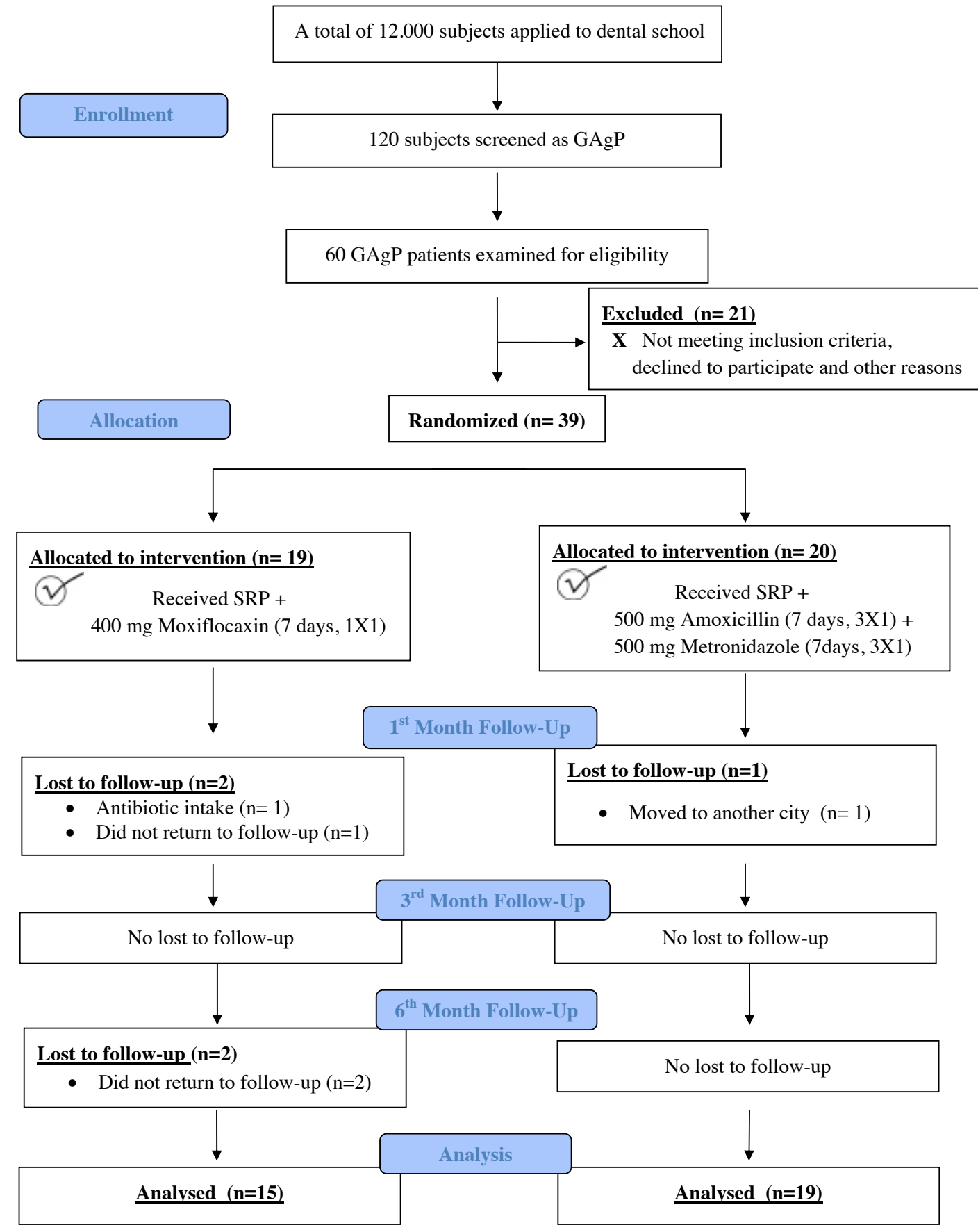

Fig. 1. Flow diagram of the study according to CONSORT 2010. 
While one subject from AMX+MET group was withdrawn at 1st month visit, four subjects from MXF group were withdrawn at $1^{\text {st }}$ and $6^{\text {th }}$ month visits. Fifteen subjects in the MXF group ( 7 males and 9 females; mean age, 30.32 \pm 3.81 years; range, 24-35 yrs) and 19 subjects in the AMX+MET group ( 9 males and 10 females; mean age, 30.95 \pm 3.66 yrs; range, 25-35 years) completed the study (Table 1). There were no significant differences between the groups at any point related to age, gender, and smoking status. $(p>0.05)$ (Table 1).

Each subject of the MXF group received 7 tablets of MXF $400 \mathrm{mg}$ and each subject of the AMX+MET group received a total of 21 tablets of AMX $500 \mathrm{mg}$ and MET $500 \mathrm{mg}$. month in the MXF group and in the $3^{\text {rd }}$ month in the AMX+MET group compared to the baseline $(p<0.01)$. However, these differences were not significant compared to other follow-up visits. No difference was found between groups at any point in 6 months.

The mean PD reduction and the mean clinical attachment gain at the $6^{\text {th }}$ month were $1.17 \pm 0.16 \mathrm{~mm}$ and $0.64 \pm 0.12$ $\mathrm{mm}$, respectively, in MXF group and $1.42 \pm 0.41$ and $0.70 \pm 0.20 \mathrm{~mm}$, respectively, in AMX+MET group. No significant differences were observed between groups. The changes as percentage in PD and CAL are also evaluated under 3 categories, as $<4 \mathrm{~mm}$ (shallow), 4-6 $\mathrm{mm}$ (moderate) and $>6 \mathrm{~mm}$ (severe) (8). Percentage of $\mathrm{PD}$ was increased to $27.56 \%$ in pockets initially $<4$

Table 1. Demographic and clinical characteristics of the GAgP patients.

\begin{tabular}{|c|c|c|c|}
\hline Baseline Parameters & $\begin{array}{c}\text { MXF Group } \\
(\mathrm{N}=19)\end{array}$ & $\begin{array}{c}\text { AMX + MET Group } \\
(\mathbf{N}=20)\end{array}$ & $p$-value \\
\hline $\begin{array}{l}\text { Age }(\text { mean years } \pm \mathrm{SD}) \\
(\min -\max )\end{array}$ & $\begin{array}{c}30.95 \pm 3.66 \\
(24-35) \\
\end{array}$ & $\begin{array}{c}30.22 \pm 3.90 \\
(25-35) \\
\end{array}$ & NS \\
\hline Female / Male (n) & $9 / 10$ & $10 / 10$ & NS \\
\hline Smokers (n) & $5(26 \%)$ & $6(30 \%)$ & NS \\
\hline Plaque Index ${ }^{*}$ & $2.39 \pm 0.39$ & $2.45 \pm 0.42$ & NS \\
\hline Gingival Index ${ }^{*}$ & $1.41 \pm 0.22$ & $1.25 \pm 0.29$ & NS \\
\hline Probing Depth ${ }^{*}(\mathrm{~mm})$ & $4.19 \pm 0.62$ & $4.57 \pm 1.08$ & NS \\
\hline Bleeding on Probing $^{*}(\%)$ & $66 \pm 0.16$ & $67 \pm 0.17$ & NS \\
\hline Clinical Attachment Loss ${ }^{*}(\mathrm{~mm})$ & $4.94 \pm 0.81$ & $5.31 \pm 1.14$ & NS \\
\hline $\begin{array}{l}\text { Demographic features of AgP } \\
\text { patients completing the study }\end{array}$ & $\begin{array}{c}\text { MXF Group } \\
(\mathbf{n}=15)\end{array}$ & $\begin{array}{c}\text { AMX + MET Group } \\
(n=19)\end{array}$ & $p$-value \\
\hline $\begin{array}{l}\text { Age }^{*}(\text { mean years } \pm \text { SD }) \\
(\min -\max )\end{array}$ & $\begin{array}{c}30.32 \pm 3.81 \\
(24-35) \\
\end{array}$ & $\begin{array}{c}30.95 \pm 3.66 \\
(25-35) \\
\end{array}$ & NS \\
\hline Female / Male (n) & $9 / 7$ & $10 / 9$ & NS \\
\hline Smokers $(\mathrm{n}, \%)$ & $4, \% 26.6$ & $8, \% 42.1$ & NS \\
\hline
\end{tabular}

* Mean $\pm \mathrm{SD}, \mathrm{NS}=$ Difference between groups is not statistically significant $(p$-value $>0.05)$.

While none of the test subjects reported any adverse event associated with MXF, two subjects reported a stomachache and one subject reported gastrointestinal problems related to AMX+MET intake.

Both groups demonstrated statistically a significant decrease in all clinical periodontal parameters at the end of the $1^{\text {st }}$, $3^{\text {rd }}$ and $6^{\text {th }}$ months compared to the baseline (PI; $p<0.001$ and GI, PD, BOP, CAL, $p<0.01$, Tables 2 and 3).

There were no significant differences between the $1^{\text {st }}$ and $3^{\text {rd }}$, and $3^{\text {rd }}$ and $6^{\text {th }}$ month in the groups whereas none of the periodontal parameters showed intergroup differences in any time points $(p>0.01)$, except GI at $6^{\text {th }}$ months $(p<0.05)$ (Tables 2 and 3)

As shown in table 3 , both groups demonstrated statistically a significant decrease in PD and CAL at the $1^{\text {st }}, 3^{\text {rd }}$ and $6^{\text {th }}$ month compared to the baseline $(p<0.01)$. While the greatest reduction in the mean PD was seen at the $3^{\text {rd }}$ month, compared to the baseline in both groups $(p<0.01)$, but this difference was not statistically significant compared to the $1^{\text {st }}$ and the $6^{\text {th }}$ month. The greatest reduction in the mean CAL was seen during the $1^{\text {st }}$ $\mathrm{mm}$ in MXF group and $33.61 \%$ in AMX+MET group (Table 4), and no difference was seen between groups. Percentage of PD was decreased by $14.99 \%$ in pockets initially $4-6 \mathrm{~mm}, 12.65$ in pockets initially $>6 \mathrm{~mm}$ in MXF group, and $14.75 \%$ and $17.80 \% \%$ in AMX+MET group, respectively (Table 4) and no differences were seen between groups.

Percentage of CAL was increased by $46.70 \%$ in pockets initially $<4 \mathrm{~mm}$ in MXF group and by $42.10 \%$ in AMX+MET group (Table 5), and there was no significant difference between the groups. Percentage of CAL was decreased by $26.70 \%$ in CAL initially $>6 \mathrm{~mm}$, $20.00 \%$ in CAL initially $4-6 \mathrm{~mm}$ in MXF group, and $26.30 \%$ and $15.8 \%$ in AMX+MET group, respectively. No differences were observed between the groups; however, there was a significant difference between the $1^{\text {st }}$ and the $3^{\text {rd }}$ month in CAL 4-6 mm category in MXF group $(p<0.05)$.

There were no differences between groups in any categories at any time. 
Table 2. Median (25th-75th percentiles) values for plaque index (PI), gingival index (GI) and bleeding on probing (BOP) of $\mathrm{MXF}$ and AMX+MET groups for each recalls.

\begin{tabular}{|c|c|c|c|c|c|c|c|c|c|c|c|}
\hline & & MXF Group & & & & & $\begin{array}{c}\text { AMX + MET } \\
\text { Group }\end{array}$ & & & & \\
\hline \multirow[t]{4}{*}{ PI } & Baseline & $\begin{array}{c}2.39 \\
(2.25-2.48)\end{array}$ & & & & & $\begin{array}{c}2.53 \\
(2.33-2.71)\end{array}$ & & & & \\
\hline & $1 \mathrm{~m}$ & $\begin{array}{c}0.07 \\
(0-0.11)\end{array}$ & $\mathrm{a}$ & & & & $\begin{array}{c}0.07 \\
(0-0.21)\end{array}$ & $\mathrm{d}$ & & & \\
\hline & $3 \mathrm{~m}$ & $\begin{array}{c}0.22 \\
(0.08-0.34)\end{array}$ & $+\dagger$ & & $\mathrm{b}$ & & $\begin{array}{c}0.27 \\
(0-0.41)\end{array}$ & $+\dagger$ & $\dagger$ & $\mathrm{e}$ & \\
\hline & $6 \mathrm{~m}$ & $\begin{array}{c}0.22 \\
(0.12-0.37)\end{array}$ & +1 & 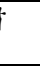 & & $\mathrm{c}$ & $\begin{array}{c}0.18 \\
(0.07-0.34) \\
\end{array}$ & $\longrightarrow$ & $\dagger$ & & $\mathrm{f}$ \\
\hline \multirow[t]{4}{*}{ GI } & Baseline & $\begin{array}{c}1.38 \\
(1.26-1.48)\end{array}$ & & & & & $\begin{array}{c}1.27 \\
(1-1.54) \\
\end{array}$ & & & & \\
\hline & $1 \mathrm{~m}$ & $\begin{array}{c}0.14 \\
(0-0.19)\end{array}$ & $\mathrm{a}$ & & & & $\begin{array}{c}0.028 \\
(0-0.14)\end{array}$ & $\mathrm{d}$ & & & \\
\hline & $3 \mathrm{~m}$ & $\begin{array}{c}0.14 \\
(0-0.19)\end{array}$ & $=$ & $\dagger$ & b & & $\begin{array}{c}0.03 \\
(0-0.14)\end{array}$ & $+\dagger$ & & e & \\
\hline & $6 \mathrm{~m}$ & $\begin{array}{c}0.35 \\
(0-0.67)\end{array}$ & & $\dagger$ & & $\mathrm{c}$ & $\begin{array}{c}0.14 \\
(0.06-0.3)\end{array}$ & + & $\dagger$ & & $f$ \\
\hline \multirow[t]{4}{*}{ BOP } & Baseline & $\begin{array}{c}0.65 \\
(0.52-0.77)\end{array}$ & & & & & $\begin{array}{c}0.72 \\
(0.56-0.8)\end{array}$ & - & & & \\
\hline & $1 \mathrm{~m}$ & $\begin{array}{c}0.11 \\
(0.1-0.2)\end{array}$ & a & & & & $\begin{array}{c}0.14 \\
(0.06-0.21)\end{array}$ & d & & & \\
\hline & $3 \mathrm{~m}$ & $\begin{array}{c}0.24 \\
(0.17-0.29)\end{array}$ & & $\dagger$ & $\mathrm{b}$ & & $\begin{array}{c}0.16 \\
(0.1-0.22)\end{array}$ & ]$^{\dagger}$ & $\dagger$ & $\mathrm{e}$ & \\
\hline & $6 \mathrm{~m}$ & $\begin{array}{c}0.27 \\
(0.14-0.36)\end{array}$ & & $\dagger$ & & $\mathrm{c}$ & $\begin{array}{c}0.14 \\
(0.1-0.2)\end{array}$ & $\dagger$ & $\dagger$ & & $f$ \\
\hline
\end{tabular}

a: Significant difference between baseline and $1 \mathrm{~m}(p<0.01)$ for MXF group

b: Significant difference between baseline and $3 \mathrm{~m}(p<0.01))$ for MXF group

c: Significant difference between baseline and $6 \mathrm{~m}(p<0.01))$ for MXF group

$*$ : Significant difference between groups for GI at $6 \mathrm{~m}(p<0.05)$

d: Significant difference between baseline and $1 \mathrm{~m}(p<0.01)$ for AMX + MET group

e: Significant difference between baseline and $3 \mathrm{~m}(p<0.01)$ for AMX + MET group

f: Significant difference between baseline and $6 \mathrm{~m}(p<0.01)$ for AMX + MET group

$\dagger$ : No significant difference between $1^{\text {st }}$ and $3^{\text {rd }}$ months and $3^{\text {rd }}$ and $6^{\text {th }}$ months in and between AMX + MET and MXF groups.

Table 3. Mean \pm standard deviation (minimum-maximum) values for probing depth (PD) and clinical attachment loss (CAL) of each recall.

\begin{tabular}{|c|c|c|c|c|c|c|c|c|c|}
\hline & & MXF Group & & & & AMX + MET Group & & & \\
\hline \multirow[t]{5}{*}{ PD } & Baseline & $\begin{array}{l}4.18 \pm 0.62 \\
(2.98-5.45)\end{array}$ & 7 & 7 & & $\begin{array}{c}4,57 \pm 1.08 \\
(2.88-5.21) \\
\end{array}$ & & $\overline{7}$ & 二 \\
\hline & $1 \mathrm{~m}$ & $\begin{array}{l}2.91 \pm 0.38 \\
(2.4-4.02)\end{array}$ & $a^{a}$ & & & $\begin{array}{c}3.12 \pm 0.68 \\
(1.91-4.86)\end{array}$ & $\mathrm{d}$ & & \\
\hline & $3 \mathrm{~m}$ & $\begin{array}{l}2.79 \pm 0.33 \\
(2.31-3.7)\end{array}$ & & $\mathrm{b}^{\mid}$ & & $\begin{array}{c}3.11 \pm 0.6 \\
(2.15-4.82)\end{array}$ & $\square_{\dagger}$ & $e^{1}$ & \\
\hline & $6 \mathrm{~m}$ & $\begin{array}{l}3.01 \pm 0.46 \\
(2.53-4.17\end{array}$ & $\dagger$ & & $\mathrm{c}$ & $\begin{array}{c}3.15 \pm 0.67 \\
(2.35-5.44)\end{array}$ & $+\dagger$ & & $\mathrm{f}$ \\
\hline & & & & & & & & 7 & \\
\hline \multirow[t]{4}{*}{ CAL } & Baseline & $\begin{array}{c}4.94 \pm 0.81 \\
(3.76-6.56)\end{array}$ & - & 7 & & $\begin{array}{c}5.03 \pm 1.14 \\
(3.65-8.87)\end{array}$ & & & \\
\hline & $1 \mathrm{~m}$ & $\begin{array}{l}4.14 \pm 0.87 \\
(2.9-6.08)\end{array}$ & $a^{a}$ & & & $\begin{array}{c}4.37 \pm 0.87 \\
(3.06-6.44)\end{array}$ & $\mathrm{d}$ & & \\
\hline & $3 \mathrm{~m}$ & $\begin{array}{c}3.98 \pm 0.82 \\
(3.07-5.72)\end{array}$ & $\dagger \dagger$ & $\mathrm{b}$ & & $\begin{array}{c}4.41 \pm 0.93 \\
(3.27-7.01)\end{array}$ & ${ }^{\dagger}$ & $\mathrm{e}$ & \\
\hline & $6 \mathrm{~m}$ & $\begin{array}{c}4.3 \pm 0.93 \\
(2.96-6.56)\end{array}$ & $y_{\dagger}$ & & $\mathrm{c}$ & $\begin{array}{c}4.33 \pm 0.94 \\
(3.23-7.02)\end{array}$ & $\dagger$ & & $\mathrm{f}$ \\
\hline
\end{tabular}

a: Significant difference between baseline and $1 \mathrm{~m}(p<0.01)$ for MXF group b: Significant difference between baseline and $3 \mathrm{~m}(p<0.01))$ for MXF group c: Significant difference between baseline and $6 \mathrm{~m}(p<0.01))$ for MXF group d: Significant difference between baseline and $1 \mathrm{~m}(p<0.01)$ for AMX + MET group e: Significant difference between baseline and $3 \mathrm{~m}(p<0.01)$ for AMX + MET group f: Significant difference between baseline and $6 \mathrm{~m}(p<0.01)$ for AMX + MET group $\dagger$ : No significant difference between $1^{\text {st }}$ and $3^{\text {rd }}$ months and $3^{\text {rd }}$ and $6^{\text {th }}$ months in and between AMX + MET and MXF groups. 
Table 4. Alterations of probing depth (PD) (a) and clinical attachment loss (CAL) (b) categories as percentage among recall periods for the groups. (a) Probing depth (PD) categories (\%).

\begin{tabular}{|c|c|c|c|c|c|c|c|c|}
\hline & & Baseline & $1^{\text {st }}$ month & $\begin{array}{c}\text { Difference } \\
\text { between } \\
\text { Baseline-1 }^{\text {st }} \\
\text { month }\end{array}$ & $3^{\text {rd }}$ month & $\begin{array}{c}\text { Difference } \\
\text { between } \\
\text { Baseline-3 }^{\text {rd }} \\
\text { month }\end{array}$ & $6^{\text {th }}$ month & $\begin{array}{c}\text { Difference } \\
\text { between } \\
\text { Baseline- } 6^{\text {th }} \\
\text { month }\end{array}$ \\
\hline \multirow{2}{*}{$\begin{array}{c}\text { PD }<4 \text { mm } \\
\text { (Shallow) }\end{array}$} & $\begin{array}{l}\text { MXF } \\
\text { Group }\end{array}$ & 58.33 & 85.20 & $26.87 * *$ & 89.88 & $31.55^{* *}$ & 85.89 & $27.56 * * *$ \\
\hline & $\begin{array}{l}\text { AMX + } \\
\text { MET } \\
\text { Group }\end{array}$ & 48.33 & 81.04 & $32.71 * *$ & 82.70 & $34.37 * *$ & 81.94 & $33.61 * *$ \\
\hline \multirow[b]{2}{*}{$\begin{array}{l}\text { PD 4-6 mm } \\
\text { (Moderate) }\end{array}$} & $\begin{array}{c}\text { MXF } \\
\text { Group }\end{array}$ & 26.91 & 11.59 & $15.32 *$ & 8.47 & $18.44 *$ & 11.92 & $14.99 *$ \\
\hline & $\begin{array}{l}\text { AMX + } \\
\text { MET } \\
\text { Group }\end{array}$ & 29.37 & 15.28 & $14.09 *$ & 14.25 & $15.12 *$ & 14.62 & $14.75^{*}$ \\
\hline \multirow[b]{2}{*}{$\begin{array}{c}\text { PD > } 6 \mathrm{~mm} \\
\text { (Severe) }\end{array}$} & $\begin{array}{l}\text { MXF } \\
\text { Group }\end{array}$ & 14.82 & 1.79 & $13.03 *$ & 1.80 & $13.02 *$ & 2.17 & $12.65^{*}$ \\
\hline & $\begin{array}{l}\text { AMX + } \\
\text { MET } \\
\text { Group }\end{array}$ & 21.24 & 2.40 & $18.84 *$ & 3.05 & $18.19 *$ & 3.44 & $17.80 *$ \\
\hline
\end{tabular}

* : Significant difference between baseline and $1^{\text {st }} \mathrm{m}, 3^{\text {rd }} \mathrm{m}$ and $6^{\text {th }} \mathrm{m}(p<0.05)$

** : Significant difference between baseline and $1^{\text {st }} \mathrm{m}, 3^{\text {rd }} \mathrm{m}$ and $6^{\text {th }} \mathrm{m}(p<0.01)$

*** : Significant difference between baseline and $1^{\text {st }} \mathrm{m}, 3^{\text {rd }} \mathrm{m}$ and $6^{\text {th }} \mathrm{m}(p<0.001)$

Table 5. Alterations of probing depth (PD) (a) and clinical attachment loss (CAL) (b) categories as percentage among recall periods for the groups. (b) Clinical attachment loss (CAL) categories (\%).

\begin{tabular}{|c|c|c|c|c|c|c|c|c|}
\hline & & Baseline & $\begin{array}{c}1^{\text {st }} \\
\text { month }\end{array}$ & $\begin{array}{c}\text { Difference } \\
\text { between } \\
\text { Baseline-1 } \\
\text { month } \\
\end{array}$ & $\begin{array}{c}3^{\text {rd }} \\
\text { month }\end{array}$ & $\begin{array}{c}\text { Difference } \\
\text { between } \\
\text { Baseline- } \\
\mathbf{3}^{\text {rd }} \text { month } \\
\end{array}$ & $\begin{array}{c}6^{\text {th }} \\
\text { month }\end{array}$ & $\begin{array}{c}\text { Difference } \\
\text { between } \\
\text { Baseline-6 } \\
\text { month } \\
\text { month }\end{array}$ \\
\hline \multirow[b]{2}{*}{ CAL $<4$ mm } & MXF Group & 13.30 & 53.30 & $40.00 * * *$ & 73.30 & $60.00 * * *$ & 60.00 & $46.70 * * *$ \\
\hline & $\begin{array}{l}\text { AMX + MET } \\
\text { Group }\end{array}$ & 5.30 & 36.80 & $31.50 * *$ & 42.10 & $36.80 * *$ & 47.40 & $42.10 * *$ \\
\hline \multirow[b]{2}{*}{ CAL 4-6 mm } & MXF Group & 46.70 & $33.30^{\mathrm{a}}$ & $13.40 *$ & 20 & $26.70 *$ & 26.70 & $20.00 *$ \\
\hline & $\begin{array}{l}\text { AMX + MET } \\
\text { Group }\end{array}$ & 47.40 & 42.10 & 5.30 & 36.80 & 10.60 & 31.60 & $15.80 *$ \\
\hline \multirow[b]{2}{*}{$\mathrm{CAL}>6 \mathrm{~mm}$} & MXF Group & 40.00 & 13.30 & $26.70 * *$ & 6.70 & $13.30 *$ & 13.30 & $26.70 * *$ \\
\hline & $\begin{array}{l}\text { AMX + MET } \\
\text { Group }\end{array}$ & 47.40 & 21.10 & $26.30 * *$ & 21.10 & $26.30 * *$ & 21.10 & $26.30 * *$ \\
\hline
\end{tabular}

*: Significant difference between baseline and $1^{\text {st }} \mathrm{m}, 3^{\text {rd }} \mathrm{m}$ and $6^{\text {th }} \mathrm{m}(p<0.05)$

**: Significant difference between baseline and $1^{\text {st }} \mathrm{m}, 3^{\text {rd }} \mathrm{m}$ and $6^{\text {th }} \mathrm{m}(p<0.01)$

***: Significant difference between baseline and $1^{\text {st }} \mathrm{m}, 3^{\text {rd }} \mathrm{m}$ and $6^{\text {th }} \mathrm{m}(p<0.001)$

a: Significant difference between $1^{\text {st }}$ and $3^{\text {rd }}$ months $(p<0.05)$

\section{Discussion}

To our knowledge, this study was the first clinical study, which evaluates the effects of systemic moxifloxacin compared to the adjunctive systemic amoxicillin and metronidazole as an adjunct to nonsurgical treatment in the treatment of patients with GAgP. On the basis of the present findings, it can be concluded that adjunctive moxifloxacin provides comparable clinical improvement to that of the combination of amoxicillin and metronidazole in the treatment of GAgP.

All periodontal clinical parameters were dramatically decreased in both groups at the $1^{\text {st }}$ month compared to the baseline and all patients maintained good hygiene and post-treatment follow-ups. In the present study, although no effort was made to control the smoking; smokers were equally distributed between groups and the results did not change (data not shown).

Management of $\mathrm{AgP}$ is always challenging for clinicians since every case is unique and there are no established treatment guidelines or protocols. In the treatment of $\mathrm{AgP}$, a number of antimicrobial regimens have been investigated, which aim to potentiating the effects of SRP. It was shown that nonsurgical treatment together with systemic use of antibiotics in $\mathrm{AgP}$ yields better clinical results and less surgery needs (9-11) when comparing nonsurgical treatment alone $(1,2,12)$. 
In the present study, there were no differences in, and between the groups at any time. Then, we categorized the parameters as slight, moderate, and severe (Tables 4 and 5). There was also no difference between the groups. However, when each patient was evaluated as a separate entity, it was found that the alterations in the frequencies of CAL categories were significantly different at all times in both groups.

The mean for the full-mouth PD reduction and the clinical attachment gain were better (13) or comparable $(4,8,10-12)$ to those reported in patients with GAgP at the $6^{\text {th }}$ month. However, it is not convenient to make direct comparisons between the studies due to discrepancies among the study methodologies.

In the treatment of $\mathrm{AgP}$, different antibiotic regimens, length of antibiotic therapy, timing of the administration, different dosages, evaluation parameters and clinical outcome assessments have been studied, however there is no consensus or definite conclusion, yet $(2,9)$. As stated by Mombelli et al. (9); "Useful antibiotic regimes for distinct clinical or microbiological conditions could not be clearly identified based on available evidence," "The optimal timing for antibiotic administration is still controversial", hence, "There are no evidence based guidelines for the use of systemically administered antibiotics (14)."

Different amoxicillin and metronidazole dosages used by the researchers in the studies. In the present study, $500 \mathrm{mg}$ of both amoxicillin and metronidazole, three times a day were prescribed for each person to reach a minimum effective concentration of antibiotics in gingival crevicular fluid and blood.

The timing of the antibiotic regime is still unclear, however, based on studies and reviews, Consensus Report of the Sixth European Workshop on Periodontology concluded that antibiotic intake should start on the day of non-surgical treatment (15).

Duration of the antibiotic regime also changes between the studies. Nevertheless, to date, there is no clear statement about the duration of the antibiotic use. It is concluded that the SRP should be carried out in the shortest time possible, preferably less than 7 days in $\operatorname{AgP}(15,16)$. Hence, in the present study, antibiotic administration was started after the initial periodontal treatment; in the morning of the same day of SRP, and the treatment was completed in 24 hours, using 7-day systemic antibiotic regimes for both groups.

Moxifloxacin is a fourth-generation fluoroquinolone with a broad spectrum of activity against microorganisms and pathogens with resistance to penicillin, macrolides, and tetracyclines. It contains a C-8 methoxy substitute that increases bactericidal activity and there is a marked the time-kill kinetics and post-antibiotic effect (17). Moxifloxacin is effective and generally very well tolerated by patients and the reported side effects are very low. It is expected that the patient's compliance might be enhanced since prescribing a single-dose per day is possible, due to its pharmacokinetics.

Efficacy of moxifloxacin in dental research is mostly evaluated in the treatment of odontogenic abscesses or infiltrates and promising in vitro activity against odontogenic pathogens was revealed over amoxicillin-clavulanic acid, clindamycine, doxycycline and penicillin. Moxifloxacin has a favorable bacterial activity against putative periodontal pathogens including P.g., A.a. and T. forsythia $(7,18)$. In an in vitro study, the activity of moxifloxacin was compared with ofloxacin and doxycycline against single-species biofilms of two P.g. and two A.a. strains and a multispecies biofilm consisting of 12 species and a topical formulation of moxifloxacin as an adjunct to mechanical treatment is suggested (19). The good penetration of moxifloxacin into soft and hard tissues in Wistar rats was also shown (20). Moxifloxacin was found to be comparable to that of amoxicillinclavulanate however superior to those of clindamisin, metronidazole, doxycycline or penicillin (21-23).

In a study by Müller et al. (7), it showed that A.a. strains were highly susceptible to fluoroquinolones, ciprofloxacin and moxifloxacin. Some of the adjunctive antibiotics are secreted in saliva in insufficient concentrations to inhibit A.a. Moxifloxacin seems to be secreted in saliva at higher levels than in plasma and may also concentrate at the site of infection since it penetrates polymorphonuclear granulocytes and epithelial cells (7).

In the present study, to potentiate the outcomes of nonsurgical periodontal treatment, SRP performed in 24-h period in combination with chlorhexidine digluconate mouthrinse and systemically administered antibio tics by reducing the number of periodontopathogen not only from periodontal pockets but also from their other habitats such as saliva, the tongue, and by retarding recolonization of the bacteria. AgP patients might have benefits from this approach.

The present study is the use of only one type of antibiotic with less amounts of tablets; instead of two different types of antibiotics with a lot more tablets taken. This treatment alternative might cause fewer side effects with similar clinical outcomes and enhance patient compliance. In the contrary to previous reports, three patients who use AMX+MET, reported adverse effects $(4,12)$. However, other studies are reported varying side effects related to AMX+MET $(11,24,25)$. There is no report regarding adverse effects of moxifloxacin in periodontal treatment.

One would consider why a control group (without antibiotics) did not think to be included in the present study. This might be a one of the limitations of the present study. However, as we summarized and discussed in this section, the antibiotic used as an adjunct to SRP is approved with research and accepted with consensus 
reports released by EFP and AAP in the treatment of GAgP. Hence, we thought that it would not be ethical to monitor the nonsurgical treatment of patients with GAgP without an adjunct antibiotic. While the effect of adjunctive AMX+MET in the treatment of GAgP is well defined $(4,11,12,26)$, antibiotic combination of AMX+MET was considered as control.

Another limitation of the present study would be the lack of microbiological evaluation. There are two major indications for microbiological testing in Periodontology; first, to detect subgingival microbial flora for accurate diagnosis. It was stated that all patients with GAgP may not have an identical and specific microbial profile related with GAgP (27). Moreover, subgingival microbial factors in GAgP do not seem different from patients with chronic periodontitis. Prevalence and behaviors of periodontopathogens may not adapt to different populations and ethnicities $(28,29)$. It was reported that $A$.a.-positive patients had no specific benefit from AMX+MET (24), which means combinations or specific antibiotic regimens may not work in all cases (14). On the other hand, Heller et al. (26) emphasized interindividual varieties of periodontopathogens in the subgingival microbial flora of patients with GAgP and concluded that not all GAgP patients had greater microbial benefits from AMX+MET combination. The patients had species associated with GAgP were more affected from this combination.

Second, was to determine the antibiotic susceptibility/ resistance of periodontopathogenic profiles for proper treatment. It was noted that European and South American countries have significant differences in their antibiotic susceptibility profiles of periodontal bacteria (30). van Winkelhoff et al. (30) concluded that "it may not be possible to develop uniform protocols in the administration of antibiotics and in the treatment of severe type of periodontitis. More accurate approach might be as follows: to analyze the subgingival microflora, to characterize periodontopathogens, to decide for prescribing antimicrobial regime or not, and to test that antimicrobial drugs for bacterial resistance and susceptibility. Otherwise, antibiotics are not always clinically effective. Nevertheless, in most of the studies, bacterial resistance and susceptibility are disregarded and bacterial counts are reported; following administration of any antimicrobial regimes. The most optimal antibiotic regime would be determined with antibiotic susceptibility testing. On the other hand, different microbiology laboratory set-ups, hence different test reports, complex microbial flora, empiric and the misuse of antibiotics may limit to use of microbial test.

Having taken together all the provided data from other studies, it is difficult to compare and conclude adjunctive benefits of antimicrobial treatments due to both the paucity of randomized controlled studies and the dif- ferent methodologies of the studies. Moreover, suppression/eradication of targeted microorganisms does not mean to achieve clinical efficacy (9).

\section{Conclusions}

Within the limitation of the present study, we conclude that: although both antibiotic regimes together with nonsurgical treatment provided similar and favorable end results at 6 months, moxifloxacin use could be preferred by both dentists and the patients due to compliance because of the reduced number of tablets and the single-dose per day, as well as in patients with allergies, intolerance, or lack of response to amoxicillin and metronidazole. Nevertheless, antimicrobial treatment should be based on individual characteristics of the patients.

Further researches may involve individual risk assessments, and individual treatment protocols.

\section{References}

1. Haffajee AD, Socransky SS, Gunsolley JC. Systemic anti-infective periodontal therapy. A systematic review. Ann Periodontol. 2003;8:115-81.

2. Herrera D, Sanz M, Jepsen S, Needleman I, Roldan S. A systematic review on the effect of systemic antimicrobials as an adjunct to scaling and root planing in periodontitis patients. J Clin Periodontol. 2002;29 Suppl 3:136-59.

3. van Winkelhoff AJ, Rams TE, Slots J. Systemic antibiotic therapy in periodontics. Periodontol 2000. 1996;10:45-78.

4. Mestnik MJ, Feres M, Figueiredo LC, Duarte PM, Lira EA, Faveri M. Short-term benefits of the adjunctive use of metronidazole plus amoxicillin in the microbial profile and in the clinical parameters of subjects with generalized aggressive periodontitis. J Clin Periodontol. 2010;37:353-65.

5. Slots J, Research, Science and Therapy Committee. Systemic antibiotics in periodontics. J Periodontol. 2004;75:1553-65.

6. Herrera D, Alonso B, Leon R, Roldan S, Sanz M. Antimicrobial therapy in periodontitis: the use of systemic antimicrobials against the subgingival biofilm. J Clin Periodontol. 2008;35:45-66.

7. Muller HP, Holderrieth S, Burkhardt U, Hoffler U. In vitro antimicrobial susceptibility of oral strains of Actinobacillus actinomycetemcomitans to seven antibiotics. J Clin Periodontol. 2002;29:73642.

8. Varela VM, Heller D, Silva-Senem MX, Torres MC, Colombo AP, Feres-Filho EJ. Systemic antimicrobials adjunctive to a repeated mechanical and antiseptic therapy for aggressive periodontitis: a 6-month randomized controlled trial. J Periodontol. 2011;82:112130 .

9. Mombelli A, Cionca N, Almaghlouth A. Does adjunctive antimicrobial therapy reduce the perceived need for periodontal surgery?. Periodontol 2000. 2011;55:205-16.

10. Guerrero A, Griffiths GS, Nibali L, Suvan J, Moles DR, Laurell $\mathrm{L}$, et al. Adjunctive benefits of systemic amoxicillin and metronidazole in non-surgical treatment of generalized aggressive periodontitis: a randomized placebo-controlled clinical trial. J Clin Periodontol. 2005;32:1096-107.

11. Griffiths GS, Ayob R, Guerrero A, Nibali L, Suvan J, Moles $\mathrm{DR}$, et al. Amoxicillin and metronidazole as an adjunctive treatment in generalized aggressive periodontitis at initial therapy or retreatment: a randomized controlled clinical trial. J Clin Periodontol. 2011;38:43-9.

12. Aimetti M, Romano F, Guzzi N, Carnevale G. Full-mouth disinfection and systemic antimicrobial therapy in generalized aggressive periodontitis: a randomized, placebo-controlled trial. J Clin Periodontol. 2012;39:284-94. 
13. Xajigeorgiou C, Sakellari D, Slini T, Baka A, Konstantinidis A. Clinical and microbiological effects of different antimicrobials on generalized aggressive periodontitis. J Clin Periodontol. 2006;33:254-64.

14. Haffajee AD. Systemic antibiotics: to use or not to use in the treatment of periodontal infections. That is the question. J Clin Periodontal. 2006;33:359-61.

15. Sanz M, Teughels W, Group AoEWoP. Innovations in non-surgical periodontal therapy: Consensus Report of the Sixth European Workshop on Periodontology. J Clin Periodontol. 2008;35:3-7.

16. Herrera D, Matesanz P, Bascones-Martínez A, Sanz M. Local and systemic antimicrobial therapy in periodontics. J Evid Based Dent Pract. 2012;12 3Suppl:50-60.

17. Boswell FJ, Andrews JM, Wise R, Dalhoff A. Bactericidal properties of moxifloxacin and post-antibiotic effect. J Antimicrob Chemother. 1999;43 Suppl B:43-9.

18. Eick S, Schmitt A, Sachse S, Schmidt KH, Pfister W. In vitro antibacterial activity of fluoroquinolones against Porphyromonas gingivalis strains. J Antimicrob Chemother. 2004;54:553-6.

19. Tsaousoglou P, Nietzsche S, Cachovan G, Sculean A, Eick S. Antibacterial activity of moxifloxacin on bacteria associated with periodontitis within a biofilm. J Med Microbiol. 2014;63:284-92.

20. Cachovan G, Nergiz I, Thuss U, Siefert HM, Sobottka I, Oral O, et al. Penetration of moxifloxacin into rat mandibular bone and soft tissue. Acta Odontol Scand. 2009;67:182-6.

21. Milazzo I, Blandino G, Musumeci R, Nicoletti G, Lo Bue AM, Speciale A. Antibacterial activity of moxifloxacin against periodontal anaerobic pathogens involved in systemic infections. Int J Antimicrob Agents. 2002;20:451-6.

22. Flemmig TF, Petersilka G, Volp A, Gravemeier M, Zilly M, Mross $\mathrm{D}$, et al. Efficacy and safety of adjunctive local moxifloxacin delivery in the treatment of periodontitis. J Periodontol. 2011;82:96-105.

23. Tomas I, Tomas M, Alvarez M, Velasco D, Potel C, Limeres J, et al. Susceptibility of oral obligate anaerobes to telithromycin, moxifloxacin and a number of commonly used antibacterials. Oral Microbiol Immunol. 2007;22:298-303.

24. Mombelli A, Cionca N, Almaghlouth A, Decaillet F, Courvoisier DS, Giannopoulou C. Are there specific benefits of amoxicillin plus metronidazole in Aggregatibacter actinomycetemcomitans-associated periodontitis? Double-masked, randomized clinical trial of efficacy and safety. J Periodontol. 2013;84:715-24.

25. van Winkelhoff AJ, Rodenburg JP, Goené RJ, Abbas F, Winkel EG, de Graaff J. Metronidazole plus amoxycillin in the treatment of Actinobacillus actinomycetemcomitans associated periodontitis. J Clin Periodontol. 1989;16:128-31.

26. Heller D, Varela VM, Silva-Senem MX, Torres MC, Feres-Filho EJ, Colombo AP. Impact of systemic antimicrobials combined with anti-infective mechanical debridement on the microbiota of generalized aggressive periodontitis: a 6-month RCT. J Clin Periodontol. 2011;38:355-64.

27. van Winkelhoff AJ. Antibiotics in periodontics: are we getting somewhere?. J Clin Periodontol. 2005;32:1094-5.

28. Sanz M, van Winkelhoff AJ, Herrera D, Dellemijn-Kippuw N, Simon R, Winkel E. Differences in the composition of the subgingival microbiota of two periodontitis populations of different geographical origin. A comparison between Spain and The Netherlands. Eur J Oral Sci. 2000;108:383-92.

29. van Winkelhoff AJ, Winkel EG. Microbiological diagnostics in periodontics: biological significance and clinical validity. Periodontol 2000. 2005;39:40-52.

30. van Winkelhoff AJ, Herrera D, Oteo A, Sanz M. Antimicrobial profiles of periodontal pathogens isolated from periodontitis patients in The Netherlands and Spain. J Clin Periodontol. 2005;32:893-8.

\section{Acknowledgements}

This study was supported by Kocaeli University Research Foundation (2011/014 HDP). 